\title{
Slower-than-normal syntactic processing in agrammatic Broca's aphasia: Evidence from Dutch
}

\author{
Petra Burkhardt ${ }^{\mathrm{a}, \mathrm{c}, *}$, Sergey Avrutin ${ }^{\mathrm{b}}$, \\ Maria M. Piñango ${ }^{\mathrm{c}}$, Esther Ruigendijk ${ }^{\mathrm{b}, 1}$ \\ ${ }^{a}$ Department of Germanic Linguistics, University of Marburg, Wilhelm-Röpke-Straße 6A, 35032 Marburg, Germany \\ ${ }^{\mathrm{b}}$ UiL/OTS Utrecht Institute of Linguistics, Trans 10, $3512 \mathrm{JK}$ Utrecht, The Netherlands \\ ${ }^{\mathrm{c}}$ Department of Linguistics, Yale University, P.O. Box 208366, New Haven, CT 06520-8366, USA
}

Received 4 April 2006; received in revised form 4 October 2006; accepted 26 October 2006

\begin{abstract}
Studies of agrammatic Broca's aphasia reveal a diverging pattern of performance in the comprehension of reflexive elements: offline, performance seems unimpaired, whereas online - and in contrast to both matching controls and Wernicke's patients - no antecedent reactivation is observed at the reflexive. Here we propose that this difference characterizes the agrammatic comprehension deficit as a result of slower-than-normal syntactic structure formation. To test this characterization, the comprehension of three Dutch agrammatic patients and matching control participants was investigated utilizing the cross-modal lexical decision (CMLD) interference task. Two types of reflexive-antecedent dependencies were tested, which have already been shown to exert distinct processing demands on the comprehension system as a function of the level at which the dependency was formed. Our hypothesis predicts that if the agrammatic system has a processing limitation such that syntactic structure is built in a protracted manner, this limitation will be reflected in delayed interpretation. Confirming previous findings, the Dutch patients show an effect of distinct processing demands for the two types of reflexive-antecedent dependencies but with a temporal delay. We argue
\end{abstract}

\footnotetext{
*Corresponding author. Department of Germanic Linguistics, University of Marburg, Wilhelm-Röpke-Straße 6A, 35032 Marburg, Germany. Tel.: + 496421 2824645; fax: + 4964212824558.

E-mail addresses: petra.burkhardt@aya.yale.edu (P. Burkhardt), sergey.avrutin@let.uu.nl (S. Avrutin), maria.pinango@yale.edu (M.M. Piñango), esther.ruigendijk@uni-oldenburg.de (E. Ruigendijk).

${ }^{1}$ Present address: Institut für Fremdsprachenphilologien Fk. III, Carl von Ossietzky Universität Oldenburg, 26129 Oldenburg, Germany.
} 
that this delayed syntactic structure formation is the result of limited processing capacity that specifically affects the syntactic system.

(C) 2006 Elsevier Ltd. All rights reserved.

Keywords: Agrammatism; Online sentence comprehension; Reflexivity; Processing limitation; Dutch

\section{Agrammatism and sentence comprehension}

It is well-known that sentence comprehension is partially impaired in agrammatic Broca's aphasia (referred to here as 'agrammatism') ${ }^{2}$ (Caramazza \& Zurif, 1976; Grodzinsky, 2000). Across languages, agrammatic patients exhibit difficulties during the processing of agentive passives, agentive object relatives and agentive object clefts. One factor that these sentence types have in common is that they all require the establishment of a so-called filler-gap dependency, which leads to a non-canonical interpretation (e.g., the agent of the action appears after the patient of the action). This observation has led to movement-based characterizations of the agrammatic comprehension deficit (cf. Grodzinsky, 1990; Grodzinsky, 1995; Grodzinsky, Piñango, Zurif, \& Drai, 1999; Hagiwara, 1993; Swinney, Zurif, Prather, \& Love, 1996; Zurif, Swinney, Prather, Solomon, \& Bushell, 1993; inter alia; but see Piñango, 2000 and Friedmann, this issue, for a discussion of non-movement derived structures). Yet, it has also been known for some time now that agrammatic patients also show processing difficulties during the establishment of certain referential dependencies required for pronominal interpretation, which crucially, are not dependent on syntactic displacement. Whereas agrammatic patients show generally good comprehension for reflexives, they show poor comprehension for pronouns (cf. Choy \& Thompson, 2005; Edwards, Varlokosta, \& Payne, 2003; Friederici, Weissenborn, \& Kail, 1991; Grodzinsky, Wexler, Chien, Marakovitz, \& Solomon, 1993; Jarema \& Friederici, 1994; Love, Nicol, Swinney, Hickok, \& Zurif, 1998; Piñango, 2002; Piñango \& Burkhardt, 2001, 2005; Ruigendijk, Vasić, \& Avrutin, 2006; Vasić, Avrutin, \& Ruigendijk, 2006). In light of these two kinds of observations concerning displaced constituents on the one hand, and pronominal expressions on the other, a generalization suggests itself: agrammatic comprehension fails whenever the underlying syntactic representation is unable to properly constrain the possible interpretations that the comprehension system can contemplate for a sentence. In fact, it is only in those cases where correct interpretation depends exclusively on the proper implementation of syntactic structure that the agrammatic comprehension system predictably fails.

Turning to referential interpretation, the comprehension patterns observed are not homogeneous across tasks. In offline tasks, research shows above-chance performance for reflexives and increased difficulty for pronouns, while, in online tasks, agrammatic patients show deficient - but qualitatively distinct - performance for reflexives and pronouns, i.e. no reactivation effects at the reflexive (but see below for details) and reactivation of a syntactically unavailable antecedent for pronouns.

\footnotetext{
${ }^{2}$ There is consensus in the field to use the term 'agrammatism' to refer to a language deficit that is characteristic of patients who suffered brain lesions in Broca's region, the underlying white matter and the areas surrounding it in the left hemisphere. We also use this label, but note that if taken literally, the term is in fact too strong under the theoretical account taken herein, because we claim that our patients do have grammar, but are affected by a processing limitation that crucially impacts syntactic structure building.
} 
It is this divergence between offline and online performance for reflexives that leads to the present study which is based on the fundamental observation shared, throughout most of the literature, that the deficit of agrammatic patients is best understood as a processing limitation, and crucially, that this limitation targets a specific component of the language system: the building of syntactic structure in a timely manner. This view is based on the observation of a temporal delay at all levels of comprehension that are related to syntactic structure formation: in lexical activation (e.g., Haarmann \& Kolk, 1991, 1994; Prather, Zurif, Love, \& Brownell, 1997), movement-based dependencies (e.g., Burkhardt, Piñango, \& Wong, 2003; Love, Swinney, \& Zurif, 2001), and non-movement-based dependencies (e.g., Piñango \& Burkhardt, 2005).

In the present study, we investigate online comprehension of agrammatic patients and probe referential interpretation of reflexive entities in Dutch. This approach is motivated by previous observations on pronominal interpretation in English-speaking agrammatic patients showing delayed sentence implementation of reflexive interpretation (Piñango \& Burkhardt, 2005). The results support the view that agrammatic sentence comprehension is subject to a processing deficiency targeting syntactic structure building, since the interpretation of these pronominals depends on the formation of syntactic representation. This result together with previously reported evidence predicts that this general feature of agrammatic comprehension should be observed cross-linguistically.

In seeking to show this cross-linguistic convergence, we capitalize on differences in reflexivity marking between English and Dutch; English uses a SELF anaphor (himself) in structures where Dutch has a SE anaphor (zich), which, in contrast to the English SELF anaphor is not specified for gender or number features. This cross-linguistic difference has consequences for how the dynamic implementation of reflexivity takes place not only in the normal (cf. Reinhart \& Reuland, 1993; Reuland, 2001), but also in the impaired system.

In what follows, we first discuss the slow-syntax hypothesis as a processing-based description of the agrammatic deficit. We then present the representational and processing considerations involved in reflexive interpretation as it concerns two types of reflexiveantecedent dependencies available in the language system-coargument reflexives and logophors - which differ specifically in the way they implement their interpretive demands. We end with the presentation of a new set of experimental results which, to forecast, show the predicted convergence between Dutch and English in the way pronominal implementation is carried out in agrammatic comprehension.

\section{Slowed-down syntactic structure formation}

There is agreement in the literature that the deficit in the comprehension of agrammatic patients is not one of knowledge loss, but one of an inability to properly implement this knowledge (e.g., Avrutin, 2004a, b; Burkhardt et al., 2003; Friederici, Wessels, Emmorey, \& Bellugi, 1992; Grodzinsky, 1995; Haarmann \& Kolk, 1991, 1994; Mauner, Fromkin, \& Cornell, 1993; Piñango, 2000, 2002, but see Grodzinsky \& Friederici, 2006 for a view that attributes both a knowledge and a processing characterization to agrammatic comprehension). Here, we seek to further specify the nature of this limitation by showing that it is driven by an insufficient instantiation of syntactic structure formation (e.g., Haarmann \& Kolk, 1991, 1994; Piñango, 2000; Piñango \& Burkhardt, 2005). Specifically, our slow syntax characterization proposes that it is the Merge operation (e.g., Chomsky, 1995), a process whereby two syntactic categories are combined to form a larger constituent in the 
phrase structural representation, that is critically delayed in the agrammatic system, thus yielding the observed pattern of impairment. ${ }^{3}$ This view is supported by online comprehension studies that revealed that agrammatic patients show delayed priming effects in filler-gap constructions ${ }^{4}$ (Burkhardt et al., 2003; Love et al., 2001), suggesting that these dependencies become available with a temporal delay in the agrammatic system in comparison to the unimpaired system. Furthermore, as a result of the slowed-down implementation of syntactic information, competing sources of information become available in the agrammatic system that are extra-syntactic in nature and driven by semantic or information structural principles (Avrutin, 2004a, b, 2006; Piñango, 2000, 2002; Piñango \& Burkhardt, 2005). This in turn results in interpretation ambiguity once syntactic structure formation is completed. The availability of two competing interpretations - one guided by extra-syntactic considerations and the other guided by syntactic information that emerged in a protracted manner-is evidenced by the distinct performance patterns alluded to above in offline tasks (Avrutin, 2006; Piñango, 2000, 2002; Ruigendijk et al., 2006).

Here, we pursue the notion of slower-than-normal formation of syntactic structure through the online comprehension of referential dependencies in Dutch. The representational and processing considerations of the distribution and implementation of pronominals in this language are outlined directly below.

\section{Reflexivity}

\subsection{Representational and processing considerations}

Reflexive-antecedent dependencies are a fruitful topic of investigation since reflexive interpretation has been proposed to be subjected to distinct linguistic domains on the basis of phrase structural and predication considerations (Avrutin, 1999; Burkhardt, 2005; Reinhart \& Reuland, 1993; Reuland, 2001): if a reflexive entity is in a coargument relationship with its antecedent (exemplified in (1)), the dependency is established at the level of syntax, while in the absence of a coargument relationship (as in (2)), the dependency is formed at the level of discourse structure. This distinction is illustrated in the following examples (where subscripts mark the relevant dependencies):

(1) Philip $_{i}$ defended himself .

(2) $\mathrm{Ann}_{\mathrm{i}}$ put the toys behind herself $\mathrm{i}_{\mathrm{i}}$

\footnotetext{
${ }^{3}$ An anonymous reviewer notes that the notion of "slow merge" sponsored here predicts that agrammatic patients would be garden-pathed in the presence of attachment ambiguity. Indeed, this is predicted by the slow syntax account and reported results already bear the prediction out. Hickok, Zurif, and Canseco-Gonzalez (1993) observe that contrary to predictions of the MoveXP approach (Grodzinsky, 1990; Grodzinsky, 1995; Grodzinsky \& Friederici, 2006) comprehension of subject relatives is not normal-like throughout the completion of the sentence as is generally assumed. Specifically, in center-embedded subject relatives - such as The tiger that chased the lion is big - agrammatic patients systematically "mis-attach" the predicate complement is big to the serially connected DP the lion as opposed to the correct, but less syntactically immediate the tiger.

${ }^{4}$ Priming refers to the facilitation in recognition of one lexical item in the presence of a semantically and/or phonologically related lexical item. This can be observed not only in word-list studies, but also during the processing of sentences and larger passages, where dependency formation (e.g., in filler-gap dependencies or during referential processing) shows antecedent reactivation at the point of the gap.
} 
The predicate defended in (1) has two arguments: the reflexive himself and its antecedent Philip, i.e. the reflexive and its antecedent are coarguments of the same predicate. In contrast, the predicate put in (2) has three arguments: the DP Ann, the DP the toys and the $\mathrm{PP}$ behind herself. As a result, the reflexive and its antecedent are not immediate coarguments, but only the antecedent DP and the entire locative PP are, whereas herself is the argument of the preposition behind. These two kinds of structurally distinct reflexives are, therefore, referred to as coargument reflexives (1) and logophors (2), respectively.

Following Reinhart and Reuland's (1993) Reflexivity Theory, the notion of coargumenthood is formalized in that a "predicate is reflexive iff two of its arguments are coindexed", which is the case in (1), but crucially not in (2). In addition, a predicate "is reflexive-marked iff either [the predicate] $\mathrm{P}$ is lexically reflexive or one of $\mathrm{P}$ 's arguments is a SELF anaphor'. In English, reflexive-marking is always instantiated by the presence of a SELF anaphor. And the condition on reflexive marking is essential to prevent a dependent reading with a coindexed pronoun in a coargument relation as in ${ }^{*}$ Philip $_{i}$ defended him , $_{\text {, }}$ which is ungrammatical in English. ${ }^{5}$ Critically, when both of these conditions are met, the reflexive-antecedent dependency is formed in syntax, i.e. the linkage between the two coarguments is established at the level of syntax; otherwise, the linkage between the reflexive and its antecedent must be established at the level of discourse, where further mechanisms become available during the selection of the proper antecedent. In addition, morphological features must be matched to rule out a dependent reading as in $*$ Philip $_{i}$ defended herself ${ }_{i}$.

Since this paper is concerned with reflexivity in Dutch, we briefly turn to the particular properties of Dutch illustrated by (3) and (4), which are the counterparts of (1) and (2) above.

(3) Philip $_{i}$ verdedigde zich $_{i}$.

(4) $\mathrm{Ann}_{\mathrm{i}}$ legde het speelgoed achter $\mathrm{zich}_{\mathrm{i}}$.

Generally, Dutch employs two different types of reflexives: SELF anaphors (e.g., hemzelf, zichzelf) and SE anaphors (zich). For the purposes of this paper, we are particularly interested in the instantiation of SE anaphors, which are morphologically underspecified and only carry person features, but more will be said about this in Section 3.2. Just as in English, the predicate in (3) is reflexive because two of its arguments are coindexed, while this condition is not fulfilled in (4), yielding a discourse-based dependency right away in this latter case. However, Dutch differs from English in how it accomplishes reflexive marking because it has a number of lexically reflexive predicates such as verdedigde in (3) (in addition to utilizing the option of a SELF anaphor with certain predicates). As a consequence, the presence of an intrinsically reflexive predicate suffices to establish a linkage between the reflexive zich and its coargument antecedent, and this constellation is considered the computationally cheapest way to establish a dependency (cf. Reuland, 2001). This indicates that the mechanisms available for the

\footnotetext{
${ }^{5}$ Another characteristic of the distinction between coargument reflexives and logophors is related to this observation: coargument reflexives, which fulfill the condition on reflexive marking, are in complementary distribution with ordinary pronouns, which violate reflexive marking (as illustrated in the example in the main text). Logophors, in contrast, emerge in environments in which they are interchangeable with ordinary pronouns (e.g., Ann ${ }_{i}$ put the toy behind her ${ }_{i}$ ). This interchangeability of logophors and pronouns has minute interpretive consequences, which are for instance discussed in Kuno (1987).
} 
establishment of coargument dependencies in Dutch rely on basic processes guided by phrase structural information.

Two crucial processing factors must be coupled with these theoretical considerations. First, the level at which the reflexive-antecedent dependency is established is determined through the notion of coargumenthood which is guided by phrase structural information (yielding a reflexive predicate), i.e. in the presence of coargumenthood (coupled with proper reflexive-marking), a syntax-based dependency is established. By contrast, absence of coargumenthood between the pronominal and a matching antecedent forces the system to establish the dependency at the level of discourse. ${ }^{6}$ Therefore, if the formation of phrase structure is protracted in the agrammatic system - as suggested by the slower-than-normal account sketched above - this should affect the formation of reflexive-antecedent dependencies. Following our claim of a slowing-down of the Merge operation, if the merging of elements and the building of phrase structure is protracted, the status of coargumenthood cannot be assessed on time. The second crucial observation is that discourse-based dependencies are computationally more costly than syntax-based dependencies (cf. Avrutin, Lubarsky, \& Greene, 1999; Burkhardt, 2005; de Vincenzi, 1996; Hickok \& Avrutin, 1996; Reuland, 2001; Shapiro, 2000). This computational cost is measurable during real-time comprehension, which allows us to tap into online sentence processing through an investigation of the two types of reflexive entities identified in this section.

In a series of studies with college-aged, neurologically intact participants, the online comprehension of coargument reflexives and logophors was investigated in English and Dutch (Burkhardt, 2005). Utilizing the cross-modal lexical decision (CMLD) interference paradigm, participants were asked to perform two tasks simultaneously: a listening comprehension task and a lexical decision task to an unrelated probe word. The reaction times (RTs) to the lexical decision task were recorded, and higher RTs were firstly considered to reflect increased computational demands in the primary comprehension task and were secondly attributed to extra-syntactic processes (cf. Piñango, Zurif, \& Jackendoff, 1999; Shapiro, Zurif, \& Grimshaw, 1987). For both English and Dutch, the comprehension of logophors elicited significantly higher RTs (measured immediately after the reflexive entity) compared to that of coargument reflexives, supporting the view that processing discourse-based logophor-antecedent dependencies is more costly than processing syntax-based coargument reflexive-antecedent dependencies. These findings served as a starting point for further investigations into the time course of the processing of reflexivity in agrammatism since they reveal that dependency formation can be assessed right after the reflexive entity in the intact system.

\subsection{Reflexivity in agrammatic comprehension}

There are task-related differences in the comprehension patterns of agrammatic patients, which can be accounted for by slower-than-normal syntactic structure building and have been corroborated by recent investigations of the time course of processing. In this section, we revisit those studies that have dealt with the interpretation of reflexives.

\footnotetext{
${ }^{6}$ Reinhart and Reuland's approach could partially be viewed as semantic in nature, since the authors define reflexivity as conditions on predicates. However, Reflexivity Theory clearly embodies a syntactic component as well, and the authors make a distinction between semantic and syntactic predicates. We thus interpret coargumenthood as a predication relationship established over phrase structural information.
} 
In offline tasks probing coargument reflexive dependencies, the literature does not provide a consistent picture of the performance patterns of agrammatic patients. Some studies showed that agrammatic patients' performance is above chance, i.e. they are able to identify the structurally correct antecedent in the absence of time pressure. This is attested for English via truth-value judgment tasks (Grodzinsky et al., 1993; Piñango, 2002) as well as for Dutch via a sentence picture matching task (Ruigendijk et al., 2006). Other studies report difficulties for reflexive interpretation (Choy \& Thompson, 20057; Edwards et al., 2003 ; Love et al., 1998). Turning to the online findings, a more uniform picture emerges. A CMLD priming study revealed that reflexives do not prime for their antecedents as soon as they are encountered (in contrast to what was found for unimpaired participants). Love et al. (1998) presented sentences like The boxer said that the skier ${ }_{i}$ in the hospital had blamed himself for the recent injury, and the participants were asked to listen to the sentences and perform a lexical decision task to a visually presented probe word. Lexical decisions to a probe that was semantically related to the antecedent and that was presented right after the reflexive did not reveal a facilitation effect due to semantic priming in agrammatic speakers (in contrast to normal speakers and speakers with Wernicke's aphasia), which suggests that the respective dependencies had not been formed yet. ${ }^{9}$ In another study in English, the CMLD interference paradigm (see Section 3.1) was used to examine the comprehension of coargument reflexives and logophors (Piñango \& Burkhardt, 2005). The study revealed that agrammatic patients showed no interference effect for the logophors immediately after the reflexive in contrast to healthy controls; however, they did show a significant increase in the RTs for the logophors with a temporal delay at $600 \mathrm{~ms}$ after the reflexive, which supports the slow processing hypothesis.

These delayed effects during reflexive interpretation can be accounted for within a theory of slowed-down syntactic structure formation, since information pertaining to syntactic structure must be fully available for the successful establishment of reflexiveantecedent dependencies and the determination of the domain at which dependencies are to be formed. Looking at the time course of processing, the data indicate that when probed immediately after the reflexive, interpretation fails in the agrammatic aphasic system (Love et al., 1998; Piñango \& Burkhardt, 2005), indicating that syntactic information is not fully available yet. However, further downstream, correct reflexive-antecedent dependencies become available and performance approaches a normal-like pattern, at least in some studies as reported in Piñango and Burkhardt (2005). Such an improvement in performance indicates that the information required to establish proper referential dependencies emerges over time in the agrammatic system, which is predicted by our slow syntax approach.

\footnotetext{
${ }^{7}$ Choy and Thompson also report an eye-tracking experiment, where Broca's patients showed similar fixation patterns in the region after the reflexive compared to control participants, which indicates that these patients are capable of forming reflexive-antecedent dependencies. The time course of dependency formation, however, needs further investigations, since the study reports fixation over the entire region of the prepositional phrase following the reflexive, which may fall within the window during which delayed effects have been reported in cross-modal studies (Love et al., 1998; Piñango \& Burkhardt, 2005).

${ }^{8}$ Edwards et al. (2003) report that their "subjects found it harder to judge reflexives than pronouns" (p. 21). However, their data show above chance performance for reflexives $(71 \%$ correct averaged over match and mismatch conditions). The difference in behavior arises from pronoun interpretation, which in contrast to Grodzinsky et al.'s and Piñango's studies, is also above chance (76\%).

${ }^{9} \mathrm{An}$ alternative explanation for these results is that it is lexical (re)activation that is slow in the Broca's system, as for instance suggested in Prather et al. (1997). Under this view, since syntax operates on the timely availability of lexical information, syntactic structure building is slowed-down as well.
} 


\section{The present study}

So far, research on agrammatism and reflexive interpretation has provided evidence for a slower-than-normal establishment of dependencies. In the present research, we seek to provide additional evidence for this from a cross-linguistic perspective. We are also interested in whether we can narrow down the underlying mechanism impacted by the delayed processing. Given the theoretical framework adopted herein, the formation of reflexive-antecedent dependencies in English is affected by three distinct processes: (i) the phrase structural relation of coargumenthood, (ii) reflexive-marking via a SELF anaphor, (iii) morphosyntactic feature matching (including person, number and gender features in English). Protracted syntactic processing could potentially affect a combination of any one of these mechanisms. We, therefore, turn to reflexivity in Dutch, which (i) is also guided by the assessment of coargumenthood relations, (ii) achieves reflexive-marking via lexically reflexive predicates (in the experimental manipulation used herein), and (iii) has a reflexive (zich) that is morphologically underspecified and only carries person features.

Our hypothesis is that if the Merge operation is affected by the agrammatic deficit, then Dutch-speaking patients should pattern similar to English-speaking patients, because the two languages share the basic principle of coargumenthood to determine the domain at which dependencies are formed. Moreover, Reuland (2001) postulates that the mechanisms available to form a coargument relation involving SE anaphors (i.e. the Dutch case) are more economical than those involving SELF anaphors (i.e. the English case). This suggests that the mechanisms available in Dutch represent the most fundamental processes to establish reflexive-antecedent dependencies across languages. If however the establishment of reflexive-antecedent dependencies is primarily guided by morphological information, a cross-linguistic difference should emerge between the two agrammatic groups as a function of morphosyntactic feature specification. Yet, even though morphosyntactic errors are the most prominent characteristics of sentence production in agrammatic aphasia (which is characterized as telegraphic speech and omission/substitution of functional categories and inflectional morphology), there are reports indicating already that agrammatic patients can utilize morphosyntactic feature information successfully in offline comprehension tasks involving referential interpretation (Blumstein, Goodglass, Statlender, \& Biber, 1983; Vasić \& Ruigendijk, 2005). ${ }^{10}$ Vasić and Ruigendijk (2005) argue for instance that Dutch agrammatic patients have access to number and gender information during referential interpretation of pronouns in offline tasks. Therefore, we do not in principle expect a difference between the online performance of Dutch and English patients.

Hence, the aim of the present study is to extend the findings from English agrammatic comprehension to Dutch, which in contrast to English utilizes the most automatic mechanism for reflexive interpretation that is available to the language system, i.e. a SE anaphor in combination with an intrinsically reflexive predicate. It is specifically argued that the Merge operation is affected by agrammatic aphasia, allowing the prediction that Dutch-speaking patients should perform similarly to their English-speaking counterparts during the establishment of reflexive-antecedent dependencies.

\footnotetext{
${ }^{10}$ Note that this does not hold for the interpretation of non-canonical sentences. Several studies have shown that Broca's aphasia patients cannot use morphological cues (e.g., case) effectively for the interpretation of these structures (Burchert, De Bleser, \& Sonntag, 2003; Friedmann \& Shapiro, 2003).
} 


\subsection{Methods and materials}

We employed the CMLD interference paradigm to investigate the online comprehension of reflexives (as described in Section 3.1). All participants were instructed to perform two tasks - a listening comprehension task and a lexical decision task. Participants were seated in front of a computer monitor and fitted with headphones. Sentences (which had previously been recorded by a native speaker at a normal rate of speaking and digitized with a sampling rate of 22,000 samples/second) were presented auditorily over headphones and the visual probes for the lexical decision task were presented at predetermined points in time on the computer screen in front of the participants. Probes were presented in the center of the screen in white letters on a black background (using font Arial, size 48) for $500 \mathrm{~ms}$ and participants were instructed to perform the lexical decision task as quickly and as accurately as possible. Participants were asked to indicate their response by pressing a 'yes' or 'no' button on a response box (with their non-dominant hand) and RTs were recorded up to $3000 \mathrm{~ms}$ after probe presentation. The reaction time served as a measure of processing load, which we hypothesized to be significantly higher for the logophor over the coargument reflexive condition on the basis of previous findings with college-aged unimpaired participants. Three different probe points were investigated in three separate sessions of this experiment: $400 \mathrm{~ms}$ before the onset of the critical reflexive element and 100 and $600 \mathrm{~ms}$ after the offset of the critical word. The $-400 \mathrm{~ms}$ position (which fell on the predicate in the coargument reflexive condition and the noun or preposition in the logophor condition) functioned as a baseline comparison to assure that the structural differences between the two conditions did not accrue processing cost. No effects were predicted at this position. The $100 \mathrm{~ms}$ position represents the point in time at which the establishment of the reflexive-antecedent dependency resulted in increased processing demands for logophors over coargument reflexives in investigations with unimpaired participants in English and Dutch (Burkhardt, 2005). Such an interference effect was also predicted for the control group in the present experiment, while the agrammatic patients were not predicted to show an effect at this early point. Based on the slower-than-normal processing hypothesis and on findings from a similar study with English-speaking patients (Piñango \& Burkhardt, 2005), the Dutch patient group was predicted to show the interference effect at the $600 \mathrm{~ms}$ position. In contrast, the control group should no longer show a significant difference between the two conditions at this point in time.

Thirty-five pairs of experimental sentences were constructed containing either a coargument reflexive or a logophor. Sentences were constructed in pairs and for each pair, main verbs were matched for frequency (using the Instituut voor Nederlandse Lexicologie (INL) frequency count from the CELEX online database ${ }^{11}$ ), the distance between the reflexive and the antecedent was kept constant, and identical antecedents were chosen. Logophor sentences included verbs that carried a direct object and a locative PP (introduced by achter (behind), voor (in front of) or naast (next to) and containing the reflexive entity); coargument reflexive sentences were constructed around verbs that

\footnotetext{
${ }^{11}$ INL ratings were selected, which supply the plain frequency count for each word or lemma form out of the $42,380,000$ words in the CELEX corpus. The sum of the INL frequency ratings was computed from the infinitive, present and past tense, present and past participle of each verb. If the verbs within a pair did not have the same frequency count, a frequency advantage (i.e. higher frequency) was given to the verb in the logophor condition, such that a facilitating effect arising from the higher frequency should work against our prediction that logophor interpretation elicit increased RTs in contrast to coargument reflexive interpretation.
} 
allowed zich as the direct object. To avoid end-of-sentence wrap-up effects at the critical positions, all sentences continued with a subordinate clause after the reflexive entity.

(5) (a) Logophor example:

De fietser verborg een gewonnen gouden beker achter zich, ondanks het luide juichen en klappen van het blije publiek.

"The cyclist hid a won golden cup behind himself, despite the loud cheering and applauding from the happy audience'.

(b) Coargument reflexive example:

De fietser die verschrikkelijk hard gereden had troostte zich ondanks het verlies met de gedachte aan de mooie tijdrit.

"The cyclist who had cycled terribly fast comforted himself, despite the defeat with the thought of the good time-trial".

In addition, word probes were selected for each sentence pair that were entirely unrelated to the sentence material and could not form a meaningful continuation with the sentences (e.g., judo in (5) above). ${ }^{12}$ Furthermore, probes were low-frequency nouns, one or two syllables long and carried diverse phonological and acoustical properties (Shapiro Brookins, Gordon, \& Nagel, 1991, 1993). An additional 210 sentences $^{13}$ were constructed as fillers that were combined with 70 word probes and 140 non-word probes. All sentences were arranged in a pseudo-randomized and counterbalanced order and presented in two versions to the participants. After approximately every 15 items, a binary choice comprehension question was asked to check whether the participant paid attention to the sentences.

The agrammatic speakers were first trained with ten sentences that were only six to ten words long, but also interrupted with comprehension questions, to get used to the dual task and the procedure. These sentences were repeated when the participant did not answer the comprehension questions correctly, or when he or she did not feel confident yet. After these short sentences, ten sentences of the same length as the experimental items were practiced. These were also used for the healthy participants and were repeated until the participant understood the procedure and could perform the dual task. Following this training, the actual experiment began. All participants carried out the lexical decision task with their non-dominant (which was always the left) hand.

\subsection{Participants}

Three patients participated in this study who had previously been diagnosed with Broca's aphasia on the basis of the Aachen Aphasia Test (Graetz, De Bleser, \& Willmes, 1992) and clinical work-up. The AAT scores of each of the patients are provided in the Appendix A. All three patients clearly demonstrated typical non-fluent, agrammatic speech as was determined on the basis of a spontaneous speech analysis, and did not have problems interpreting reflexives in an offline task (Ruigendijk et al., 2006). They were all right-handed and native speakers of Dutch with the mean age of 54.3. All patients had

\footnotetext{
${ }^{12}$ This was based on the judgments of two of the authors as well as two additional native speakers.

${ }^{13}$ Seventy of these items were part of another study investigating the processing demands of bound variable vs. coreferential dependencies with pronouns.
} 
suffered from a left CVA, but were in stable condition at the time of testing. See Table 1 for patient profiles. Control data were gathered from 16 age- and education-matched participants (mean age: 51.6) who had no neurological disorder or language impairment. All participants were tested at all three positions over a period of 6 months with at least 4 weeks between sessions.

\subsection{Results}

Statistical analyses were performed on data pairs only. Pairs that elicited correct responses to the lexical decision task entered the analyses. Data points that were discarded included incorrect responses (i.e. answering 'no' to a letter string that represented a word of Dutch), timed-out responses (i.e. answering after the limit of $3000 \mathrm{~ms}$ ), and falling outside two standard deviations from the individual subject mean. Accordingly, $17.32 \%$ of data pairs had to be discarded in the control group and $19.05 \%$ in the patient group. There were no significant differences in the proportion of discarded responses as a function of probe position.

Statistical analyses of the mean RTs from the control group revealed a significant difference at the $100 \mathrm{~ms}$ position between logophors $(M=858.32 \mathrm{~ms}$; SD $=226.38 \mathrm{~ms})$ and coargument reflexives $(M=825.60 \mathrm{~ms} ; \mathrm{SD}=214.74 \mathrm{~ms})$ in the analyses by subject $(t(15)=-2.84, p<.006)$ and a marginal effect by item $(t(34)=-1.84, p<.07)$. No significant effects were observed at the other two positions where interference was probed, i.e. $\quad-400 \mathrm{~ms}$ (logophors: $M=843.73 \mathrm{~ms} ; \quad \mathrm{SD}=203.91 \mathrm{~ms} ;$ coargument reflexives: $M=845.87 \mathrm{~ms} ; \mathrm{SD}=214.34 \mathrm{~ms} ; t(15)=0.27, p<.40 ; t(34)=-0.13, p<.9)$ and $600 \mathrm{~ms}$ (logophors: $M=790.97 \mathrm{~ms} ; \mathrm{SD}=224.41 \mathrm{~ms}$; coargument reflexives: $M=785.20 \mathrm{~ms}$; $\mathrm{SD}=206.14 \mathrm{~ms} ; t(15)=-0.68, p<.25 ; t(34)=-0.58, p<.56)$. These findings represent a replication of the effects reported from a study with Dutch-speaking college-aged participants (Burkhardt, 2005). They further demonstrate that processing cost arises immediately after the reflexive during the interpretation of logophors (i.e. at the $100 \mathrm{~ms}$ position), and that a processing difference between the two types of reflexives has vanished at the $600 \mathrm{~ms}$ position in the intact system.

Statistical analyses of the data from the three agrammatic patients as a group revealed the following effects. At $400 \mathrm{~ms}$ before the critical word, no main effect obtained (logophors: $M=1008.12 \mathrm{~ms} ; \mathrm{SD}=100.39 \mathrm{~ms}$; coargument reflexives: $M=970.88 \mathrm{~ms}$; $\mathrm{SD}=139.21 \mathrm{~ms} ; \quad t(2)=-1.02, \quad p<.17$ ), nor at the $100 \mathrm{~ms}$ position (logophors: $M=936.59 \mathrm{~ms} ; \mathrm{SD}=48.78 \mathrm{~ms}$; coargument reflexives: $M=996.14 \mathrm{~ms} ; \mathrm{SD}=93.07 \mathrm{~ms}$; $t(2)=1.16, p<.18)$. However, at the $600 \mathrm{~ms}$ position, the agrammatic patients showed an interference effect with a higher RT to logophors $(M=1083.08 \mathrm{~ms}$; SD $=240.06 \mathrm{~ms})$ over coargument reflexives $(M=1046.76 \mathrm{~ms} ; \mathrm{SD}=223.60 \mathrm{~ms} ; t(2)=-3.66, p<.03)$. The item analyses did not reveal significant effects. These findings support the data obtained from

Table 1

Patient data $($ Tpo $=$ time post onset $)$

\begin{tabular}{lllll}
\hline Participant & Sex & Age & Tpo at first session & Cause \\
\hline 1 & Female & 58 & 11 months & CVA-left \\
2 & Male & 41 & 2 year, 6 months & CVA-left \\
3 & Female & 64 & 1 year, 6 months & CVA-left \\
\hline
\end{tabular}




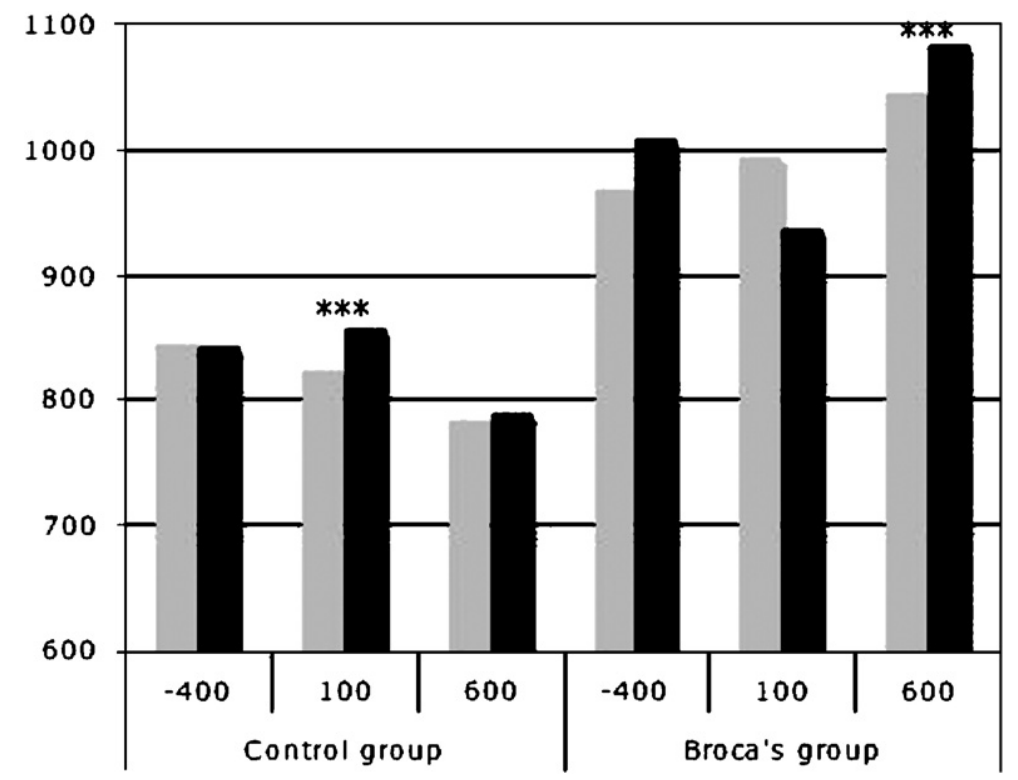

Fig. 1. Mean RTs (in ms) for the two groups per position. Coargument reflexives are plotted in gray, logophors in black.

English-speaking patients (Piñango \& Burkhardt, 2005) and, therefore, provide new evidence for a cross-linguistic validity of slower-than-normal processing. The mean RTs from the two groups are summarized in Fig. 1. The data also show that at $100 \mathrm{~ms}$ the agrammatic group registered a larger RT to the coargument reflexive condition, which is the reverse effect of the control group. This difference, however, was not statistically significant in the group analysis, and as it turns out, it can be attributed to the responses of patient 2 .

Due to the small number of patients in our agrammatic group and in order to provide additional strength to the current data, we further chose to run single-case statistics as suggested in Crawford and Garthwaite (2005). Since we predict that the unimpaired control group shows an interference effect at $100 \mathrm{~ms}$ and that this effect diminishes at $600 \mathrm{~ms}$, while the agrammatic group should show the reverse pattern, with no effect at $100 \mathrm{~ms}$ and an interference effect caused by the logophor condition at $600 \mathrm{~ms}$, we computed difference scores for these two positions and carried out Revised Standardized Difference Tests (RSDT-Crawford and Garthwaite, 2005) for each patient. The single-case analyses revealed that the performance of patient 1 differs significantly from that of the control group $(t(15)=1.71, p<.05)$ as well as the performance of patient $2(t(15)=5.38$, $p<.001)$. Patient 3 showed a marginal effect $(t(15)=0.89, p<.09)$. These additional analyses confirm the findings from the group analysis and show that agrammatic patients pattern differently from unimpaired controls during the establishment of reflexiveantecedent dependencies at 100 and $600 \mathrm{~ms}$ after the critical entity.

\section{Discussion}

The goal of this investigation has been to show the parallels between reflexive-antecedent dependencies in English and Dutch in agrammatic sentence processing as predicted by our 
proposed architecture of the syntax-discourse interface in combination with the slowsyntax generalization for agrammatic comprehension. We capitalized on a specific model of the syntax-discourse interface in combination with the inherent differences in reflexivity between English and Dutch to focus on the nature of the impairment in agrammatism. Dutch was chosen as a testing language because it allows us to better distinguish syntaxbased from discourse-based pronominal dependencies due to the availability of the SE anaphor.

The most fundamental finding from the data of the three patients is that the agrammatic deficit is closely tied to syntactic structure formation. In particular, the data demonstrate that Dutch patients are not capable of identifying reflexive-antecedent dependencies in the same temporal manner as is accomplished in the unimpaired system. In contrast to theories that postulate a loss of representational information (e.g., Grodzinsky \& Friederici, 2006), this study demonstrates that agrammatic patients resolve reflexive-antecedent dependencies in a protracted manner, supporting findings from earlier studies with English participants (Piñango \& Burkhardt, 2005). This implies, in turn, that the comprehension problem observed in agrammatism is caused by a processing limitation (as opposed to loss of knowledge), which specifically targets the temporal constraints of syntactic structure formation. Following our hypothesis, the findings suggest that this impairment is highly selective in that it affects the formation of syntactic structure proper (i.e. Merge operation). The common denominator of reflexive interpretation in English and Dutch is the coargumenthood criterion, which is determined via phrase structural information, and the fact that similar effects of delayed dependency formation are observable in these two languages suggests that the agrammatic deficit is affected by a slower-than-normal building of syntactic structure, which must be in place for proper reflexive-antecedent dependencies to be carried out. The claim that the slowing is related to structural considerations rather than reflecting task-related processing demands is further supported by subtle latency differences between structurally distinct dependencies (Burkhardt et al., 2003; Love et al., 2001) and discrete priming results for reflexives and pronouns (Love et al., 1998). If the slowing-down resulted exclusively from task-specific demands, these subtle differences in performance would not be expected. The current data thus indicate that the underlying syntactic structure formation lies at the center of this sentence comprehension impairment and impacts structure building proper (i.e. Merge) (as opposed to MoveXP). The main effect of the slowing of the Merge operation is that the arguments of a particular predicate become available at a later-than-normal processing moment. In this sense, the effect is the same for pronouns, reflexives, and logophors. But here is where the similarities end as these pronominals are distinct with respect to how they tap the language system for interpretation. In our study, we focus on the processing of coargument reflexives and logophors. In the case of the coargument reflexives (which must appear in a coargument relation with their antecedents), their presence is required for an utterance to be grammatical (otherwise the argument structure requirements are not satisfied). Thus, even if a reflexive becomes available at a later point due to the slowed process, it does become available to eventually saturate the predicate's argument slots, which explains the good offline comprehension for reflexives. A logophor, on the other hand, is not a coargument with its antecedent. Its interpretation, as we argue, is not part of the syntactic mechanism, but it is dependent on a more computationally taxing discourse-related process. Thus, as previous results demonstrated, even in an unimpaired system, the interpretation of a logophor requires more resources (and more time). Crucially, we show that in an 
agrammatic system, the same hierarchy (reflexives are cheaper than logophors) is maintained; however, it is shifted in time for both elements. The slowed-down process does influence both reflexives and logophors (processing of pronouns was not part of our study), because they are merged into the structure in a later-than-normal manner, and the cost hierarchy observed in unimpaired speech is retained, although its manifestation is shifted in time to a later point.

We would like to suggest that the delay in syntactic structure building can also account for other agrammatic comprehension patterns, as well as for-at least part of - the typical agrammatic production pattern. In terms of comprehension, the well-known chance-level performance for the interpretation of passive constructions requires the construction of a dependency relation between the element moved to subject position and its base-generated (object) position. Depending on the theoretical framework, this position is represented either as a trace or as a phonologically empty copy of the antecedent. Irrespective of the particular framework, this element is linked via syntactic dependency to the subject of the sentence and can be viewed, in a sense, as an element that is dependent for its interpretation on the subject. In unimpaired speakers, this syntactic dependency is the most economical, automatic option that they exercise based on economy considerations. However, if the syntactic system is slowed-down in agrammatic aphasia, it is possible that the dependent element (syntactically represented by the trace or the copy) may be allowed to enter into a less economical non-syntactic dependency - for example, with an antecedent that has sufficient discourse prominence, such as the referent introduced by the $b y$-phrase. The competition between the syntactic and extra-syntactic routes in agrammatism (that has consequences for production as well, see Avrutin, 2006) thus results in a chance-level performance: depending on what system wins the competition, the dependency will be established either syntactically (leading to the correct response) or extra-syntactically (resulting in possible errors). A similar line of reasoning applies to the analysis of agrammatic patients' errors in the interpretation of pronouns in complex predicate constructions, as opposed to their relatively unimpaired performance on reflexives in the same structures, for which no alternative (and incorrect) extra-syntactic dependency can be formed (see Ruigendijk et al., 2006 for details). Naturally, this reasoning can be easily extended to the chance performance on object relative clauses, object clefts, and other constructions where failure to apply syntactic dependency on time results in the availability of other types of dependencies usually blocked (in unimpaired adults) by the more efficient syntactic route. ${ }^{14}$

A brief terminological clarification is in order here: Avrutin (2004a, 2006) makes use of the term 'weak syntax' when describing the agrammatic impairment, and not of the term 'slow syntax', which was introduced by Piñango (2000). To a certain extent, the distinction is indeed only a matter of terminology. Both views agree that the fundamental problem in agrammatism is the lack of resources necessary for providing sufficient activation and both views link the slowing-down to a slower-than-normal lexical access, much in agreement with other researchers (e.g., Prather, Zurif, Love, \& Brownell, 1997, as mentioned in footnote 9). For the purposes of this study, the exact source of the slowing is not of

\footnotetext{
${ }^{14}$ See Piñango $(1999,2000,2006 a)$ for a specific instantiation of this notion which accounts not only for agentive passives but also for all constructions that turn on argument structure alternation which have been shown to be vulnerable in the agrammatic system, including agentive relative clauses and clefts, unaccusative constructions, psych-verb constructions and double object constructions.
} 
paramount importance: whatever the underlying reason is, the effect will be the same. With regard to the interpretation of referentially dependent elements (coargument reflexives and logophors), agrammatic patients exhibit a pattern qualitatively similar to that of unimpaired speakers but quantitatively distinct - the process, simply speaking, is slower.

If building syntactic structure is generally slow, processes at the left periphery (as discussed in the contributions in this issue) should be affected as well, because operations at the left periphery depend on basic building blocks. In this respect, Friedmann (this issue) proposes a unified account for the comprehension and production impairment that is related to the failure to fully construct the syntactic tree. Extending the Tree Pruning Hypothesis - the hypothesis that agrammatic speakers' failure to construct the syntactic tree properly can account for several production problems related to finite verbs, whquestions, and relative clauses (Friedmann, 2001; Friedmann \& Grodzinsky, 1997) - to the comprehension deficit may explain the comprehension difficulties with sentences that involve high syntactic nodes (i.e. passives, object-relatives). We have taken this line of reasoning one step further and propose that the agrammatic patients' failure to construct the syntactic tree completely is the result of a slower-than-normal syntactic system. In other words, slower-than-normal structure building (i.e. the Merge operation) may result in a (temporarily) pruned syntactic tree, which in turn results in specific comprehension and production problems as seen in agrammatism. This account differs in a principled manner from the well-known Trace Deletion Hypothesis (Grodzinsky, 1990; Grodzinsky, 1995) according to which it is not the operation Merge, but the operation of MoveXP that is impaired in the agrammatic system (Grodzinsky \& Friederici, 2006). A movement-based account is, however, unable to address the pattern of impairment in pronominal interpretation (since antecedent-pronominal dependencies are not movement-based), and thus fails to provide a unified account of the agrammatic sentence comprehension pattern, in contrast to the present slow-merge characterization. Additionally, as discussed above, the hypothesis that the operation of Merge is affected, can begin to account for at least part of the characteristics of agrammatic production (see Piñango, 2006b for an account for why comprehension and production impairments in agrammatism have different symptoms yet one potential source).

\section{Acknowledgments}

The second and fourth authors were supported by the project "Comparative Psycholinguistics" which is funded by the Netherlands Organisation for Scientific Research (NWO). We would like to thank John Crawford for discussing single case statistics with us, three anonymous reviewers for their helpful suggestions, and all subjects for their participation, as well as Inger Seits for helping testing control participants.

\section{Appendix A}

The numbers under spontaneous speech refer to: communicational behavior, articulation and prosody, automatic language, semantic structure, phonological structure, and syntactic structure respectively. Scores range from 0 to 5 , with 0 referring to maximum disorder, 5 minimal problems, except for syntactic structure, where 1 or 2 refer to short and syntactic incomplete utterances. Under Token Test the number of errors is given $(\max 50)$. 
Table A1

Individual scores of the aphasic speakers on the Aachen Aphasia Test Battery

\begin{tabular}{llllllll}
\hline Subject & Spontaneous speech & Token test & Written & & & \\
\cline { 3 - 7 } & & & Repetition & Language & Naming & Comprehension & Diagnosis \\
\hline 1 & $3 / 3 / 5 / 3 / 4 / 2$ & 26 & 80 & 67 & 95 & 60 & Broca \\
2 & $3 / 5 / 3 / 4 / 4 / 2$ & 18 & 112 & 82 & 99 & 107 & Broca \\
3 & $2 / 3 / 3 / 3 / 4 / 1$ & 34 & 108 & 39 & 94 & 98 & Broca \\
\hline
\end{tabular}

The maximum score for repeating is 150 , for written language 90 , for naming 120 , and for comprehension also 120 (Table A1).

Patient 1 has been tested with a shorter version of the AAT that has been developed by Heesbeen and van Loon-Vervoorn (2002). Their scores are derived from their scores on the shorter version using to the Heesbeen and van Loon-Vervoorn method.

\section{References}

Avrutin, S. (1999). Development of the syntax-discourse interface. Boston: Kluwer.

Avrutin, S. (2004a). Beyond narrow syntax. In L. Jenkins (Ed.), Variation and universals in biolinguistics (pp. 67-97). London: Elsevier.

Avrutin, S. (2004b). Optionality in child and aphasic speech. Lingue e linguaggio, 1, 95-115.

Avrutin, S. (2006). Weak syntax. In Y. Grodzinsky, \& K. Amunts (Eds.), Broca's region (pp. 49-62). Oxford: Oxford University Press.

Avrutin, S., Lubarsky, S., \& Greene, J. (1999). Comprehension of contrastive stress by Broca's aphasics. Brain and Language, 70(2), 163-186.

Blumstein, S., Goodglass, H., Statlender, S., \& Biber, C. (1983). Comprehension strategies determining reference in aphasia: A study of reflexivization. Brain and Language, 18, 115-127.

Burchert, F., De Bleser, R., \& Sonntag, K. (2003). Does morphology make the difference? Agrammatic sentence comprehension in German. Brain and Language, 87(2), 323-342.

Burkhardt, P. (2005). The syntax-discourse interface: Representing and interpreting dependencies. Amsterdam, Philadelphia: John Benjamins.

Burkhardt, P., Piñango, M. M., \& Wong, K. (2003). The role of the anterior left hemisphere in real-time sentence comprehension: Evidence from split intransitivity. Brain and Language, 86(1), 9-22.

Caramazza, A., \& Zurif, E. B. (1976). Dissociation of algorithmic and heuristic processes in language comprehension: Evidence from aphasia. Brain and Language, 3(4), 572-582.

Chomsky, N. (1995). The minimalist program. Oxford: Blackwell.

Choy, J. J., \& Thompson, C. K. (2005). Online comprehension of anaphors and pronoun constructions in Broca's aphasia: Evidence from eye-tracking. Brain and Language, 95(1), 119-120.

Crawford, J. R., \& Garthwaite, P. H. (2005). Testing for suspected impairments and dissociations in single-case studies in neuropsychology: Evaluation of alternatives using Monte Carlo simulations and revised tests for dissocations. Neuropsychology, 91, 318-331.

De Vincenzi, M. (1996). Syntactic analysis in sentence comprehension: Effects of dependency types and grammatical constraints. Journal of Psycholinguistic Research, 25(1), 117-133.

Edwards, S., Varlokosta, S., \& Payne, E. (2003). Pronominal reference and agrammatic comprehension. Brain and Language, 87, 21-22.

Friederici, A. D., Weissenborn, J., \& Kail, M. (1991). Pronoun comprehension in aphasia: A comparison of three languages. Brain and Language, 41, 289-310.

Friederici, A. D., Wessels, J. M. I., Emmorey, K., \& Bellugi, U. (1992). Sensitivity to inflectional morphology in aphasia: A real-time processing perspective. Brain and Language, 43, 747-763.

Friedmann, N. (2001). Agrammatism and the psychological reality of the syntactic tree. Journal of Psycholinguistic Research, 30, 71-90. 
Friedmann, N. (this issue) Traceless relatives: Agrammatic comprehension of relative clauses with resumptive pronouns. Journal of Neurolinguistics.

Friedmann, N., \& Grodzinsky, Y. (1997). Tense and agreement in agrammatic production: Pruning the syntactic tree. Brain and Language, 56(3), 397-425.

Friedmann, N., \& Shapiro, L. (2003). Agrammatic comprehension of simple active sentences with moved constituents: Hebrew OSV and OVS structures. Journal of Speech, Language and Hearing Research, 46(2), 288-297.

Graetz, P., De Bleser, R., \& Willmes, K. (1992). Akense afasie test. Lisse: Swets and Zeitlinger.

Grodzinsky, Y. (1990). Theoretical perspectives on language deficits. Cambridge, MA: MIT Press.

Grodzinsky, Y. (1995). Trace deletion, (theta)-roles, and cognitive strategies. Brain and Language, 51(3), 469-497.

Grodzinsky, Y. (2000). The neurology of syntax: Language use with Broca's area. Behavioral and Brain Sciences, $23(1), 1-71$.

Grodzinsky, Y., \& Friederici, A. (2006). Neuroimaging of syntax and syntactic processing. Current Opinion in Neurobiology, 16, 240-246.

Grodzinsky, Y., Piñango, M. M., Zurif, E., \& Drai, D. (1999). The critical role of group studies in neuropsychology: Comprehension regularities in Broca's aphasia. Brain and Language, 67(2), 134-147.

Grodzinsky, Y., Wexler, K., Chien, Y. C., Marakovitz, S., \& Solomon, J. (1993). The breakdown of binding relations. Brain and Language, 45(3), 396-422.

Haarmann, H. J., \& Kolk, H. H. J. (1991). Syntactic priming in Broca's aphasics: Evidence for slow activation. Aphasiology, 5(3), 247-263.

Haarmann, H. J., \& Kolk, H. H. J. (1994). On-line sensitivity to subject-verb agreement violations in Broca's aphasics: The role of syntactic complexity and time. Brain and Language, 46(4), 493-516.

Hagiwara, H. (1993). The breakdown of Japanese passives and Theta-role assignment principle by Broca's aphasics. Brain and Language, 45(3), 318-339.

Heesbeen, I., \& van Loon-Vervoorn, A. (2002). Verkorte versie van de Akense Afasietest. Uitslag tokentest is betrouwbare voorspeller. Logopedie en Foniatrie, 5, 144-150.

Hickok, G., \& Avrutin, S. (1996). Comprehension of wh-questions in two Broca's aphasics. Brain and Language, 52(2), 314-327.

Hickok, G., Zurif, E., \& Canseco-Gonzalez, E. (1993). Structural description of agrammatic comprehension. Brain and Language, 45, 371-395.

Jarema, G., \& Friederici, A. D. (1994). Processing articles and pronouns in agrammatic aphasia: Evidence from French. Brain and Language, 46, 683-694.

Kuno, S. (1987). Functional syntax: Anaphora, discourse, and empathy. Chicago: University of Chicago Press.

Love, T., Nicol, J., Swinney, D., Hickok, G., \& Zurif, E. (1998). The nature of aberrant understanding and processing of pro-forms by brain-damaged populations. Brain and Language, 65(1), 59-62.

Love, T., Swinney, D., \& Zurif, E. (2001). Aphasia and the time-course of processing long distance dependencies. Brain and Language, 79(1), 169-170.

Mauner, G., Fromkin, V. A., \& Cornell, T. L. (1993). Comprehension and acceptability judgments in agrammatism: Disruptions in the syntax of referential dependency. Brain and Language, 45(3), 340-370.

Piñango, M. M. (1999). Syntactic displacement in Broca's aphasia comprehension. In R. Bastiaanse, \& Y. Grodzinsky (Eds.), Grammatical disorders in aphasia: A neurolinguistic perspective (pp. 75-87). London: Whurr.

Piñango, M. M. (2000). On the proper generalization for Broca's aphasia comprehension pattern: Why argument movement may not be at the source of the Broca's deficit. Behavioral and Brain Sciences, 23(1), 48-49.

Piñango, M. M. (2002). Cortical reflections of two pronominal relations. In H. J. Simon, \& H. Wiese (Eds.), Pronouns-grammar and representation (pp. 233-252). Amsterdam, Philadelphia: John Benjamins.

Piñango, M. M. (2006a). Thematic roles as event structure relations. In I. Bornkessel, M. Schlesewsky, B. Comrie, \& A. D. Friederici (Eds.), Semantic role universals and argument linking: Theoretical, typological, and psycholinguistic perspectives (pp. 303-326). Berlin/New York: Mouton de Gruyter.

Piñango, M. M. (2006b). Understanding the architecture of language: The possible role of neurology. Trends in Cognitive Sciences, 10(2), 49-51.

Piñango, M. M., \& Burkhardt, P. (2001). Pronominals in Broca's aphasia comprehension: The consequences of syntactic delay. Brain and Language, 79(1), 167-168.

Piñango, M. M., \& Burkhardt, P. (2005). Pronominal interpretation and the syntax-discourse interface: Real-time comprehension and neurological properties. In A. Branco, T. McEnery, \& R. Mitkov (Eds.), Anaphora processing: linguistic, cognitive and computational modelling. Amsterdam, Philadelphia: John Benjamins. 
Piñango, M. M., Zurif, E., \& Jackendoff, R. (1999). Real-time processing implications of enriched composition at the syntax-semantics interface. Journal of Psycholinguistic Research, 28(4), 395-414.

Prather, P. A., Zurif, E., Love, T., \& Brownell, H. (1997). Speed of lexical activation in non-fluent Broca's aphasia and fluent Wenicke's aphasia. Brain and Language, 59(3), 391-411.

Reinhart, T., \& Reuland, E. (1993). Reflexivity. Linguistic Inquiry, 24(4), 657-720.

Reuland, E. (2001). Primitives of binding. Linguistic Inquiry, 32, 439-492.

Ruigendijk, E., Vasić, N., \& Avrutin, S. (2006). Reference assignment: Using language breakdown to choose between theoretical approaches. Brain and Language, 96(3), 302-317.

Shapiro, L. P. (2000). Some recent investigations of gap filling in normal listeners: Implications for normal and disordered language processing. In Y. Grodzinsky, L. Shapiro, \& D. Swinney (Eds.), Language and the brain: Representation and processing (pp. 357-376). San Diego, London: Academic Press.

Shapiro, L. P., Brookins, B., Gordon, B., \& Nagel, N. (1991). Verb effects during sentence processing. Journal of Experimental Psychology-Learning Memory and Cognition, 17(5), 983-996.

Shapiro, L. P., Zurif, E., \& Grimshaw, J. (1987). Sentence processing and the mental representation of verbs. Cognition, 27(3), 219-246.

Swinney, D., Zurif, E., Prather, P., \& Love, T. (1996). Neurological distribution of processing resources underlying language comprehension. Journal of Cognitive Neuroscience, 8(2), 174-184.

Vasić, N., Avrutin, S., \& Ruigendijk, E. (2006). Interpretation of pronouns in VP-ellipsis constructions in Dutch Broca's and Wernicke's aphasia. Brain and Language, 96(2), 191-206.

Vasić, N., \& Ruigendijk, E. (2005). The comprehension of number and gender information on pronouns in Dutch Broca's aphasia. Stem- Spraak- and Taalpathologie, 13(1), 14-24.

Zurif, E., Swinney, D., Prather, P., Solomon, J., \& Bushell, C. (1993). An on-line analysis of syntactic processing in Broca's and Wernicke's aphasia. Brain and Language, 45(3), 448-464. 